\title{
XXXIX. On a method of calculating the constant $\gamma$, expressing the relation of the specific heat at constant pressure to the specific heat at constant volume
}

\section{W. Moon}

To cite this article: W. Moon (1884) XXXIX. On a method of calculating the constant $\gamma_{\text {, }}$ expressing the relation of the specific heat at constant pressure to the specific heat at constant volume, Philosophical Magazine Series 5, 18:113, 372-373, DOI: $\underline{10.1080 / 14786448408627605}$

To link to this article: http://dx.doi.org/10.1080/14786448408627605

\section{曲 Published online: 29 Apr 2009.}

$\sqrt{6}$ Submit your article to this journal $\square$

Џلl Article views: 2

Q View related articles ¿ 
XXXIX. On a Method of Calculating the Constant $\gamma$, expressing the Relation of the Specific Heat at Constant Pressure to the Specific Heat at Constant Volume. By W. Moos*.

ET $\mathrm{H}_{1}$ equal the specific heat of air at constant pressure, and $H$ the specific heat at constant volume; then, when a volume of air is compressed through $d v$, the adiabatic pressure of the air will be $1+\frac{1}{v} d v \frac{\mathrm{H}_{1}-\mathrm{H}}{\overline{\mathrm{H}}}$ times the isothermal pressure; and if this value is equated with the pressure calculated from the work required to produce the compression, then the value of $\frac{\mathrm{H}_{1}}{\mathrm{H}}$ may be ascertained without experimentally knowing the value of $\mathrm{H}$.

The pressure may be thus calculated from the work required to produce the compression:-

If the temperature of a volume of air is increased from $t$ to $t_{1}$ (the volume being constant), then the pressure of the air will be increased from 1 to $\frac{1+t_{1} \cdot 003665}{1+t^{\circ} 003665}$; and therefore if, while the volume of air is compressed from 1 to $\frac{1}{v}$, the temperature of the air varies from $t$ to $t_{1}$, then the pressure of the air will be

$$
\frac{h}{760} 1033 \cdot 796\left(\frac{1+t_{1} \cdot 003665}{1+t^{\circ} 003665}\right) \frac{1}{v} \text { grammes, }
$$

where $h=$ barometric height, and 1033.796 the pressure upon a square centimetre at 760 millim.

The heat given off in the gas is equal to the work performed against the gas in compressing it divided by Joule's equivalent. Therefore, when the air is compressed through $d v$, the heat given off

$$
=\frac{\frac{h}{760} 1033 \cdot 796\left(\frac{1+t_{1} \cdot 003665}{1+t \cdot 003665}\right) \frac{1}{v} d v}{42355} \text { calories. }
$$

To obtain from this expression the increase of temperature of the air, it must be divided by the specific heat at constant volume and the weight of a cubic centimetre of air,

$$
\begin{aligned}
& \frac{h}{760} 1033 \cdot 796\left(\frac{1+t_{1} \cdot 003665}{1+t^{\circ} \cdot 003665}\right) \frac{1}{v} d v \\
& =\frac{42355}{\frac{\mathrm{H}}{\overline{\mathrm{H}}_{1}} \cdot 2375 \times \cdot 001293187 \frac{\hbar}{760} \frac{1}{1+\imath \cdot 003665}}\left\{\begin{array}{c}
\text { degrees } \\
\text { Centigrade. }
\end{array}\right. \\
& \text { * Communicated by the Author. }
\end{aligned}
$$


Specific Heat at Constant Pressure and Constant Volume. 373 By reducing, this equals

$$
\frac{\mathrm{H}_{1}}{\overline{\mathrm{H}}} 79 \cdot 47\left(1+t_{1} \cdot 003665\right) \frac{1}{v} d v \text { degrees Cent., }
$$

which equals the increase of temperature of the air resulting from its compression; and from this value the increase of pressure resulting from the increase of temperature may be calculated, since air tends to expand $\cdot 003665$ of its volume for each increase of a degree Centigrade beyond zero.

$$
\begin{aligned}
\therefore \frac{1+}{} & \left\{t_{1}+\frac{\mathrm{H}_{1}}{\mathrm{H}} 79 \cdot 47\left(1+t_{1} \cdot 003665\right) \frac{1}{v} d v\right\} \cdot 003665 \\
1+t_{1} \cdot 003665 & \\
= & \frac{\left(1+t_{1} \cdot 003665\right)\left(1+\frac{\mathrm{H}_{1}}{\mathrm{H}} \cdot 79 \cdot 47 \times \cdot 003665 \frac{1}{v} d v\right)}{1+t_{1} \cdot 003665} \\
= & 1+\frac{\mathrm{H}_{1}}{\mathrm{H}} \cdot 29126 \frac{1}{v} d v .
\end{aligned}
$$

Therefore when a volume of air is compressed through $d v$, it acquires a pressure adiabatically; that is $1+\frac{\mathrm{H}_{1}}{\mathrm{H}} \cdot 29126 \frac{1}{v} d v$, e pressure the air would have if compressed isothermally. By equating this value with $1+\frac{\mathrm{H}_{1}-\mathrm{H}}{\mathrm{H}} \frac{1}{v} d v$, the value of $\frac{\mathrm{H}_{1}}{\overline{\mathrm{H}}}$ may be obtained; since

$$
\begin{aligned}
& 1+\frac{\mathrm{H}_{1}}{\mathrm{H}} \cdot 29126 \frac{1}{v} d v=1+\left(\frac{\mathrm{H}_{1}}{\mathrm{H}}-1\right) \frac{1}{v} d v ; \\
\therefore & \frac{\mathrm{H}_{1}}{\mathrm{H}} \cdot 29126=\frac{\mathrm{H}_{1}}{\mathrm{H}}-1 ; \\
\therefore & \frac{\mathrm{H}_{1}}{\mathrm{H}}=\frac{1}{1-\cdot 29126}=1 \cdot 41095 .
\end{aligned}
$$

So that the value of $\frac{\mathrm{H}_{1}}{\mathrm{H}}$ or $\gamma$, determined by this method, would appear to be about $1 \cdot 41$. 